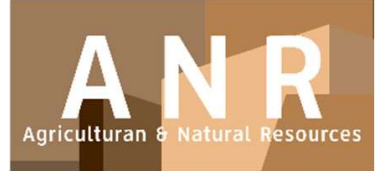

PAPER - OPEN ACCESS

\title{
Analisis Kondisi Tegakan Damar (Shorea javanica) Di Universitas Lampung Pada Masa Penanaman 2005
}

\author{
Author : Afif Bintoro \\ DOI $\quad: 10.32734 /$ anr.v3i1.829 \\ Electronic ISSN : :2654-7023 \\ Print ISSN : :2654-7015
}

Volume 3 Issue 1 - 2020 TALENTA Conference Series: Agriculturan \& Natural Resource (ANR)

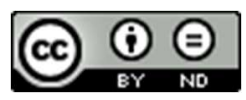

This work is licensed under a Creative Commons Attribution-NoDerivatives 4.0 International License.

Published under licence by TALENTA Publisher, Universitas Sumatera Utara

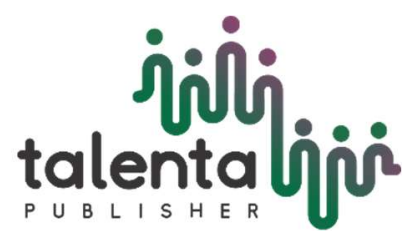




\title{
نiji (2) \\ ANR Conference Series 03 (2020)

\section{Analisis Kondisi Tegakan Damar (Shorea javanica) Di Universitas Lampung Pada Masa Penanaman 2005}

\author{
Afif Bintoro $^{\mathrm{a}}$ \\ ${ }^{a}$ Fakultas Kehutanan, Fakultas Pertanian, Universitas Lampung, Bandar lampung, Indonesia
}

\begin{abstract}
Abstrak
Damar merupakan salah satu tanaman yang banyak terdapat di Lampung dan menjadi ciri khas kota tersebut yang dikenal dengan repong damarnya. Damar termasuk dalam familia Dipterocarpaceae yang mendominasi hutan hujan tropis. Unila merupakan daerah yang beriklim tropis dan termasuk dalam wilayah hutan hujan tropis. Dalam keadaan lingkungan yang sesuai seperti yang terdapat pada daerah unila, seyogyanya damar akan mengalami pertumbuhan yang baik seperti pohon lainnya. Penelitian ini bertujuan untuk mengetahui kondisi tegakan damar berumur 14 tahun. Penelitian ini dilaksanakan di Universitas Lampung pada bulan Mei-Juni 2019. Data yang diperoleh berupa data primer dan sukunder. Pengambilan data dilakukan dengan menggunakan metode survey dengan purposive sampling yang mewakili masing-masing lokasi di Unila. Analisis data dilakukan secara kualitatif deskriptif. Hasil penelitian menunjukkan bahwa dari 100 semai yang ditanam pada tahun 2005, hanya 80 tanaman yang bertahan hidup. Dari 80 tanaman tersebut hanya 41 pohon yang ditentukan sebagai sampel. Dari data tersebut diperoleh rata-rata tinggi tanaman yaitu sebesar 3,31 m dan diameter rata-rata sebesar $6,12 \mathrm{~cm}$. Kondisi pohon beraneka ragam, namun kebanyakan pohon memiliki percabangan yang banyak dan pada pangkal percabangan batangnya banyak dijumpai seperti bintil/atau benjolan berwarna hijau seperti kanker. Selain itu daun pada pohon masih seperti tumbuhan muda atau semai dan belum menyerupai daun pohon dewasa yaitu berdaun kecil. Dari data tersebut kemungkinan yang terjadi adalah 1) keadaan tanah dan iklimnya tidak sesuai, 2) kondisi ternaungi dan tidak ternaungi, 3) tidak adanya simbiosis dengan jamur mikoriza, dan 4) adanya organisme yang menghambat pertumbuhan. Dengan kondisi tersebut, sangat disarankan untuk melakukan penelitian lanjutan guna mengatasi permasalahan tersebut agar pertumbuhan damar menjadi lebih baik.
\end{abstract}

Kata Kunci: Kondisi tegakan; Shorea javanica; Unila

\section{Pendahuluan}

Damar kaca atau disebut juga damar mata kucing (Shorea javanica) merupakan tumbuhan dari famili Dipterocarpaceae yang merupakan tumbuhan daerah hutan hujan tropis, sehingga permudaan buatan seharusnya tidak mengalami banyak kendala. Lampung merupakan daerah yang beriklim tropis dan termasuk hutan hujan tropis dengan suhu berkisar $22-30^{\circ} \mathrm{C}$ dengan curah hujan 2500-3500 mm/tahun. Dengan demikian penanaman semai damar kaca di Bandar Lampung seharusnya tidak menemui banyak masalah.

Damar mata kucing menyebar terbatas secara alami di Sumatra (di pesisir barat, mulai dari Aceh selatan ke selatan dan di pesisir timur mulai dari Palembang ke selatan) dan di Jawa Tengah. Pohon ini banyak ditemukan pada berbagai tipe lahan baik di hutan primer maupun sekunder, di atas tanah kering atau yang tergenang secara periodik, di tempat datar atau yang berlereng hingga ketinggian 300 (-500) m dpl. Pada lokasi penelitian, damar ditemukan tumbuh paling baik pada tanah lempung yang dalam, dengan curah hujan tahunan rata-rata $3.300 \mathrm{~mm}$ tanpa musim kemarau yang berarti. Ketika baru tumbuh, Semai damar memerlukan naungan, akan tetapi setelah mencapai tinggi $1 \mathrm{~m}$ damar dapat bertahan di tempat yang sedikit terbuka, dan setelah mencapai tinggi 3-4 m damar memerlukan cahaya penuh untuk tumbuh menjadi besar [1]. 
Degradasi repong damar yang ditandai dengan menurunnya keanekaragaman hayati dan luas repong secara cepat di Kabupaten Pesisir Barat mengindikasikan bahwa tindakan konservasi perlu dilakukan dengan segera ditangani melalui pendekatan yang terintegrasi (integrated approach) dengan mempertimbangkan multi-aspek yang meliputi: aspek ekologi, ekonomi, sosial, budaya, kebijakan, dan teknis [2].

Namun pada kenyataannya, pertumbuhan damar di Unila masih di bawah standar. Tegakan damar yang ditanam pada tahun 2005 sampai sekarang (sekitar 14 tahun) masih banyak yang mengalami pertumbuhan abnormal seperti berukuran kecil dan pada tanaman yang tinggi mengalami pertumbuhan yang sangat lambat. Pada pertumbuhan normal, biasanya damar yang berumur 10 tahun sudah masuk pada fase tiang (diameter $>10 \mathrm{~cm}$, tinggi di atas 5 meter).

Kondisi pertumbuhan damar yang abnormal dilokasi tersebut perlu dianalisis sehingga dapat diketahui faktorfaktor penyebab terjadinya abnormalitas pada damar tersebut. Hasil analisis sangat diperlukan untuk mengetahui tindakan yang tepat agar pertumbuhan yang tidak normal pada damar dilokasi tersebut dapat diatasi. Adapun tujuan penelitian ini adalah untuk mengetahui sebaran tinggi dan diameter tanaman damar kaca dan menganalisis faktorfaktor penyebab terhambatnya pertumbuhan damar kaca.

\section{Metode Penelitian}

Penelitian ini dilaksanakan di Universitas Lampung pada bulan Mei sampai Juni 2019. Data yang diperoleh berupa data primer dan data sekunder. Data primer adalah tinggi dan diameter pohon sampel serta foto tanaman damar (damar mata kucing/damar kaca) yang ditanam pada tahun 2005. Adapun data sekunder adalah data pohon yang ditanam pada tahun 2005 dan data pohon damar yang terdapat pada buku Keanekaragaman Pohon di Kampus Hijau Unila [3].

Pengambilan data dilakukan dengan metode survey dengan purposive sampling yang mewakili masing-masing lokasi di Unila. Pohon damar yang ditanam pada tahun 2005 berjumlah 100 individu pohon dan tersebar di Unila (data belum ditemukan). Pada buku yang ditulis oleh [3], disebutkan beberapa lokasi penyebaran damar mata kucing (damar kaca). Beberapa lokasi tersebut adalah di sebelah kiri rektorat yaitu terdapat 13 pohon, di belakang rektorat terdapat 8 pohon, di sebelah utara jalan 2 jalur barat Rektorat atau Arboretum UPT Komputer (gedung TIK) terdapat 43 pohon, di kompleks Fakultas Pertanian terdapat 1 pohon, di kompleks Fakultas MIPA terdapat 8 pohon, di Arboretum Fakultas Pertanian terdapat 3 pohon, di Arboretum Lembaga Bahasa terdapat 4 pohon, di median jalan 2 jalur sebelah barat Rektorat terdapat 14 pohon dan di median jalan sebelah barat Masjid Al Wasi'i sampai dengan pintu gerbang masuk Unila terdapat 2 pohon.

Beberapa lokasi di Unila tidak ditemukan pohon damar. Beberapa lokasi tersebut berada di tempat parkir rektorat, disekitar GSG, sekitar Perpustakaan, kandang rusa, serta diarboretum sebelah barat Perpustakaan. Jumlah total pohon damar adalah 96 pohon dengan 4 pohon lainnya sudah tidak ada. Data yang diperoleh kemudian diolah dalam bentuk tabel dan dinalisis secara deskriptif kualitatif berdasarkan sejarah pembangunan repong damar [4] serta dengan pustaka yang mendukung.

\section{Hasil dan Pembahasan}

Hasil dari penelitian ini adalah sebagai berikut:

Tabel 1. Hasil pengamatan damar mata kucing di Unila

\begin{tabular}{llllll}
\hline Nomor Pohon & Tinggi $(\mathrm{m})$ & Diameter $(\mathrm{cm})$ & Nomor Pohon & Tinggi $(\mathrm{m})$ & Diameter $(\mathrm{cm})$ \\
\hline Pohon 1 & 1,6 & 7,32 & Pohon 22 & 2,3 & 4,45 \\
Pohon 2 & 3,0 & 7,96 & Pohon 23 & 3,2 & 8,59 \\
Pohon 3 & 5,0 & 8,59 & Pohon 24 & 8,0 & 6,36 \\
Pohon 4 & 2,0 & 6,36 & Pohon 25 & 5,5 & 4,77 \\
Pohon 5 & 5,0 & 8,28 & Pohon 26 & 2,0 & 5,73 \\
Pohon 6 & 4,0 & 6,50 & Pohon 27 & 3,0 & 4,77 \\
Pohon 7 & 6,0 & 7,96 & Pohon 28 & 2,0 & 5,41 \\
Pohon 8 & 4,0 & 6,36 & Pohon 29 & 2,3 & 5,73 \\
\hline
\end{tabular}




\begin{tabular}{llllll}
\hline Pohon 9 & 2.5 & 5,41 & Pohon 30 & 2,3 & 5,41 \\
Pohon 10 & 4,0 & 7,32 & Pohon 31 & 8,0 & 7,96 \\
Pohon 11 & 5,0 & 8,91 & Pohon 32 & 1,7 & 3,82 \\
Pohon 12 & 4,0 & 9,23 & Pohon 33 & 1,0 & 3,50 \\
Pohon 13 & 4,5 & 8,28 & Pohon 34 & 3,5 & 5,41 \\
Pohon 14 & 2,5 & 8,59 & Pohon 35 & 2,0 & 3,82 \\
Pohon 15 & 3,7 & 8,28 & Pohon 36 & 2,7 & 4,77 \\
Pohon 16 & 7,0 & 7,96 & Pohon 37 & 2,0 & 2,86 \\
Pohon 17 & 6,0 & 10,82 & Pohon 38 & 1,0 & 3,50 \\
Pohon 18 & 2,0 & 5,41 & Pohon 39 & 1,6 & 3,50 \\
Pohon 19 & 2,0 & 4,45 & Pohon 40 & 2,0 & 4,14 \\
Pohon 20 & 1,8 & 4,77 & Pohon 41 & 1,0 & 2,86 \\
Pohon 21 & 3,0 & 4,77 & Rata-rata & 3,3 & 6,00 \\
\hline
\end{tabular}

Menurut masyarakat sekitar, beberapa pohon damar yang mengalami kerusakan seperti batang patah, tumbuh kerdil, tumbuh sangat lambat, dan mati telah dijumpai sejak dulu. Kerusakan dan kematian pohon damar tersebut disebabkan oleh beberapa jenis hama yang menyerang pohon damar secara langsung. Serangan hama tersebut menyebabkan kerusakan pada pohon damar sehingga pertumbuhan pohon terganggu bahkan menyebabkan kematian. Selain hama, faktor mekanis/fisik juga merupakan penyebab kerusakan pohon. Faktor mekanis/fisik menyebabkan luka terbuka pada pohon damar. Luka terbuka tersebut menjadi pintu masuk bagi hama dan penyakit. Sayangnya masyarakat belum mengetahui upaya pengendalian hama-hama tersebut. Jika tidak segera diatasi, hama tersebut dapat membahayakan kelangsungan hidup tanaman damar dan dapat menurunkan hasil produksi.

Menurut Lubis (1997) dalam [4] tradisi pembukaan lahan hutan yang dilakukan oleh masyarakat Krui secara garis besar dapat dibedakan atas tiga fase produktif yang ketiganya berlangsung di ruang fisik yang sama, namun berada pada ruang yang berbeda dalam perspektif kognitif masyarakat Krui. Ketiga fase tersebut adalah (i) Fase dakhak (ladang) yaitu fase ketika lahan siap tanam mulai ditanami dengan tanaman-tanaman subsistensi, seperti padi dan palawija, (ii) Fase kebun adalah fase bagi tanaman muda (annual crop) yang mana berkebun merupakan alasan utama dalam pengambilan keputusan untuk membuka lahan hutan, dan (iii) Fase repong dimana masyarakat Krui mulai menanamkan lahan pertaniannya dengan repong.

Damar mata kucing (Shorea javanica) termasuk dalam famili Dipterocarpaceae, dengan klasifikasi sebagai berikut:

Diviso : : Spermatophyta

Fillum : Angiospermae

Kelas : Dicotyledone

Sub Kelas : Dialypetalae

Ordo : Theales/Guttiferales

Famili : Dipterocarpaceae

Genus : Shorea

Species : Shorea javanica (Wikipedia Ensiklopedia bebas).

Damar mata kucing umumnya berbuah 4-5 tahun sekali dan biji yang dihasilkan hanya mampu bertahan selama 10 hari. Masyarakat Krui menanam pohon damar di bawah tegakan kopi selama 4-6 tahun. Dengan demikian pertumbuhan damar sangat tergantung pada naungan kopi atau pohon yang digunakan untuk tajar tanaman lada.

Penyadapan pertama dilakukan pada umur 15-20 tahun sejak penanaman dan dapat menghasilkan resin selama 30-50 tahun. Teknik penyadapan dilakukan dengan membuat lubang atau takik sadap dengan arah jalur bawah-atas. Setiap batang dibuat 2-3 jalur takik dengan jarak $25-30 \mathrm{~cm}$. Jarak takik secara vertikal dibuat sekitar $50 \mathrm{~cm}$ dengan jumlah sampai 15 takik. Sehingga pada setiap pohon terdapat 22-45 lubang getah damar. Getah damar hasil sadapan memiliki mutu yang berbeda-beda. Mutu dan kualitas getah bergantung pada hasil kegiatan yang dilakukan.

Menurut [4], secara ekologis fase perkembangan tegakan damar menyerupai tahapan suksesi hutan alam dengan segala keuntungan ekologisnya, seperti perlindungan tanah, evolusi iklim mikro, dan lain sebagainya. Dari segi teknis 
budidaya, tahap-tahap penanaman tanaman produktif, mulai dari tanaman subsisten sampai dengan tanaman tua, perawatannya disengaja atau tidak oleh petani yang berlangsung dalam kondisi ekologis yang sesuai, maka semua komponen ekologis akan saling mendukung satu sama lain. Dengan demikian proses-proses produksi yang terkait dalam seluruh tahapan pengembangan tegakan damar dapat lebih efisien dalam penggunaan faktor-faktor produksi.

Berbeda dengan pohon damar mata kucing pada umumnya, damar mata kucing di Unila yang ditanam sejak tahun 2005 mengalami pertumbuhan yang tidak normal. Pohon damar yang telah berusia 14 tahun seperti yang terdapat di Unila seharusnya sudah memiliki diameter batang sebesar $10 \mathrm{~cm}$ dan dapat dilakukan penyadapan untuk diambil getahnya. Namun kenyataan dilapangan menunjukkan bahwa tanaman damar di Unila masih berukuran sangat kecil dan hanya memiliki nilai rata-rata diameter sebesar $6 \mathrm{~cm}$.

Tanaman damar yang diamati di Universitas Lampung mengalami pertumbuhan yang sangat tidak bagus. Kondisi tanah yang tidak sesuai untuk ditanami pohon damar, faktor ternaungi atau tidak ternaungi, serta adanya serangan hama dan/atau penyakit diduga menjadi penyebab terganggunya pertumbuhan pohon damar.

Menurut Tata et al. 2008 dalam [2], Spesies Dipterocarpaceae tumbuh secara alami di hutan hujan tropis dataran rendah yaitu sekitar 0-500 meter di atas permukaan laut. Menurut Orwa et al. 2009 dalam [2], S. javanica dapat tumbuh baik di hutan primer dan sekunder pada tempat kering atau basah di tanah datar atau lereng hingga 300-500 mdpl.

Pertumbuhan tanaman dapat terhambat apabila tanah dalam keadaan tandus dan sangat minim unsur hara. Tanah semacam ini tidak dapat memenuhi kebutuhan unsur hara sehingga tidak mampu mendukung pertumbuhan tanaman. Kekurangan unsur hara tertentu seperti N, P dan K akan menghambat pertumbuhan tanaman. Selain itu adanya mikoriza juga sangat berpengaruh terhadap pertumbuhan. Tanaman yang berasal dari famili Dipterocarpaceae sangat tergantung pada mikoriza. Sehingga tanaman yang berasal dari family ini akan mengalami hambatan dalam pertumbuhannya apabila pada lokasi tempat tumbuhnya tidak terdapat atau minim mikoriza. Mikoriza dapat juga berperan sebagai biofertilizer yang dapat membantu dalam penyerapan unsur-unsur hara $\mathrm{N}, \mathrm{P}$, dan $\mathrm{K}$.

Namun apabila dugaan terganggunya pertumbuhan damar disebabkan oleh faktor kesuburan tanah, maka lahan di Unila tidak akan dapat menumbuhkan pohon jenis lain dengan baik. Hasil observasi menunjukkan bahwa pohon damar yang terganggu pertumbuhannya tumbuh diantara pohon-pohon jenis lain yang tumbuh dengan subur (gambar 1) sehingga dapat diketahui bahwa terdapat faktor lain yang menyebabkan terganggunya pertumbuhan damar mata kucing dilokasi tersebut.

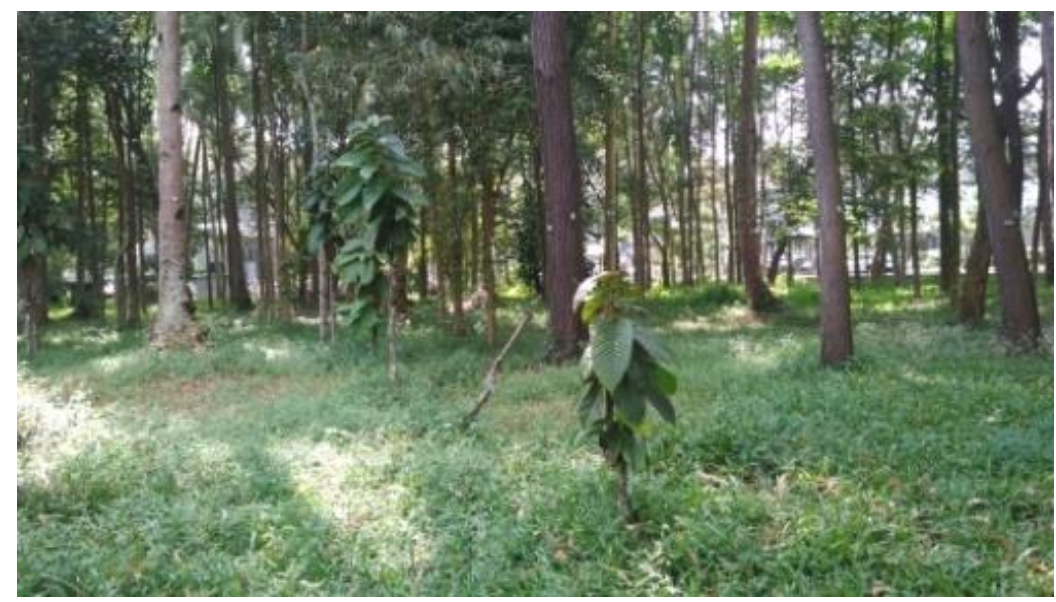

Gambar 1. Tanaman damar di antara pepohonan lain di dalam arboretum.

Selain faktor kondisi tanah, kanopi pohon yang menaungi damar dapat menjadi faktor terhambatnya pertumbuhan damar tersebut. Damar mata kucing yang merupakan anggota famili Dipterocarpaceae membutuhkan naungan pada masa semai. Namun seiring pertumbuhannya, damar akan membutuhkan cahaya sehingga naungan yang menutupi harus terbuka [4]. Berbeda dengan teori diatas, berdasarkan hasil observasi dilapangan menunjukkan bahwa damar yang ternaungi dan tidak ternaungi memiliki pertumbuhan yang sama (Gambar 2). 

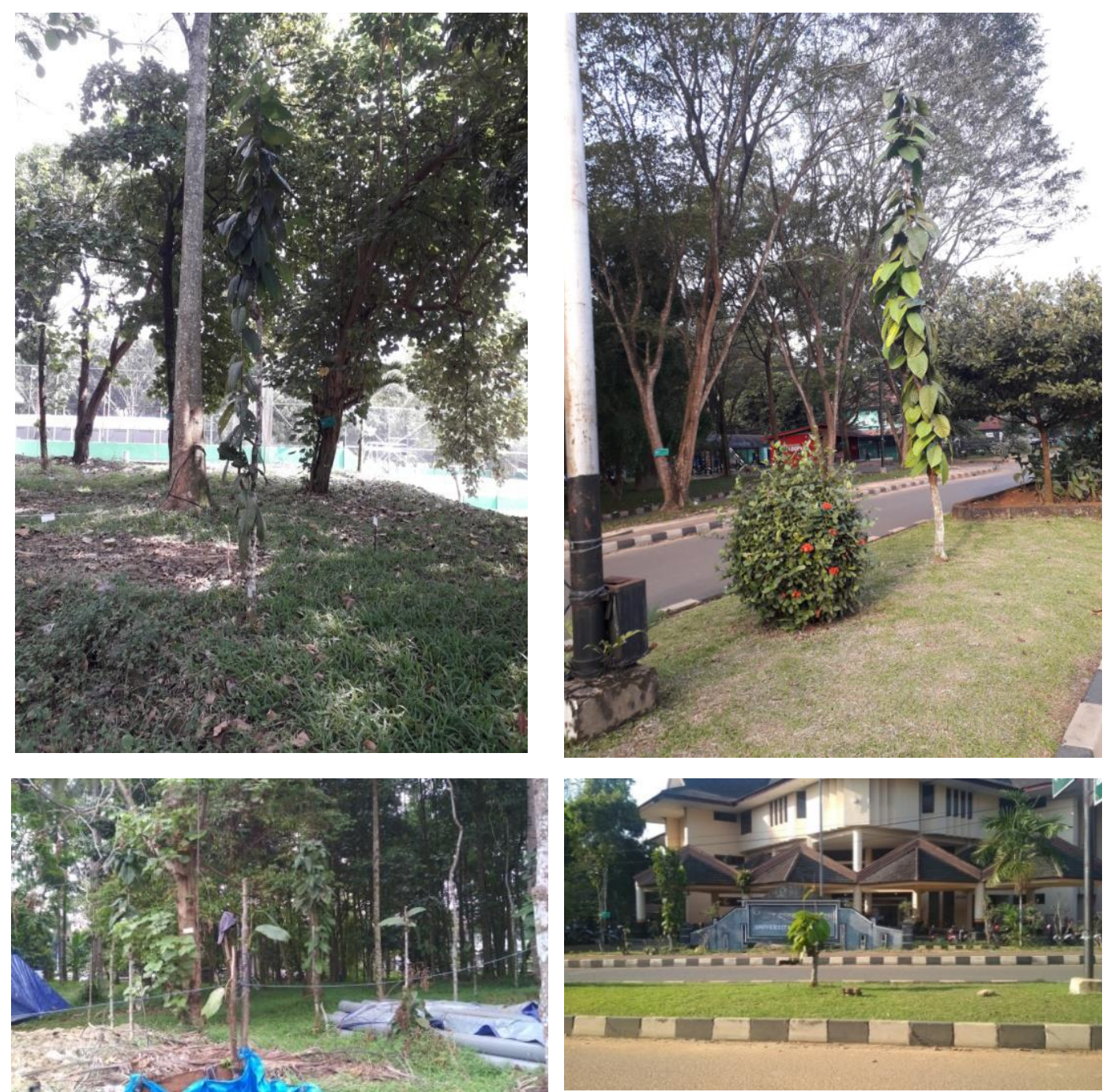

Gambar 2. Tanaman damar yang ternaungi dan tidak ternaungi

Berdasarkan hasil observasi dilapangan, pohon damar yang mendapat naungan dan pohon damar yang tidak mendapat naungan memiliki pertumbuhan yang sama. Tidak terdapat perbedaan yang signifikan antara damar yang tumbuh dibawah naungan dengan damar yang tumbuh tanpa naungan. Kedua kondisi tempat tumbuh damar tersebut menghasilkan tegakan damar yang tumbuh kerdil dan beberapa tegakan damar yang tumbuh tinggi namun tanpa cabang.

Hasil observasi juga menunjukkan bahwa terdapat beberapa tegakan damar yang terserang penyakit. Penyakit yang menyerang tanaman damar berupa benjolan yang terdapat pada batang dan terindikasi sebagai tumor (gambar 3). Penyakit ini diduga menjadi salah satu penghambat pertumbuhan pohon damar mata kucing. Benjol pada tumbuhan ini biasanya bermula dari luka pada bagian batang. Bagian tubuh yang luka kemudian akan terinfeksi penyakit sehingga menimbulkan benjolan pada batang. 

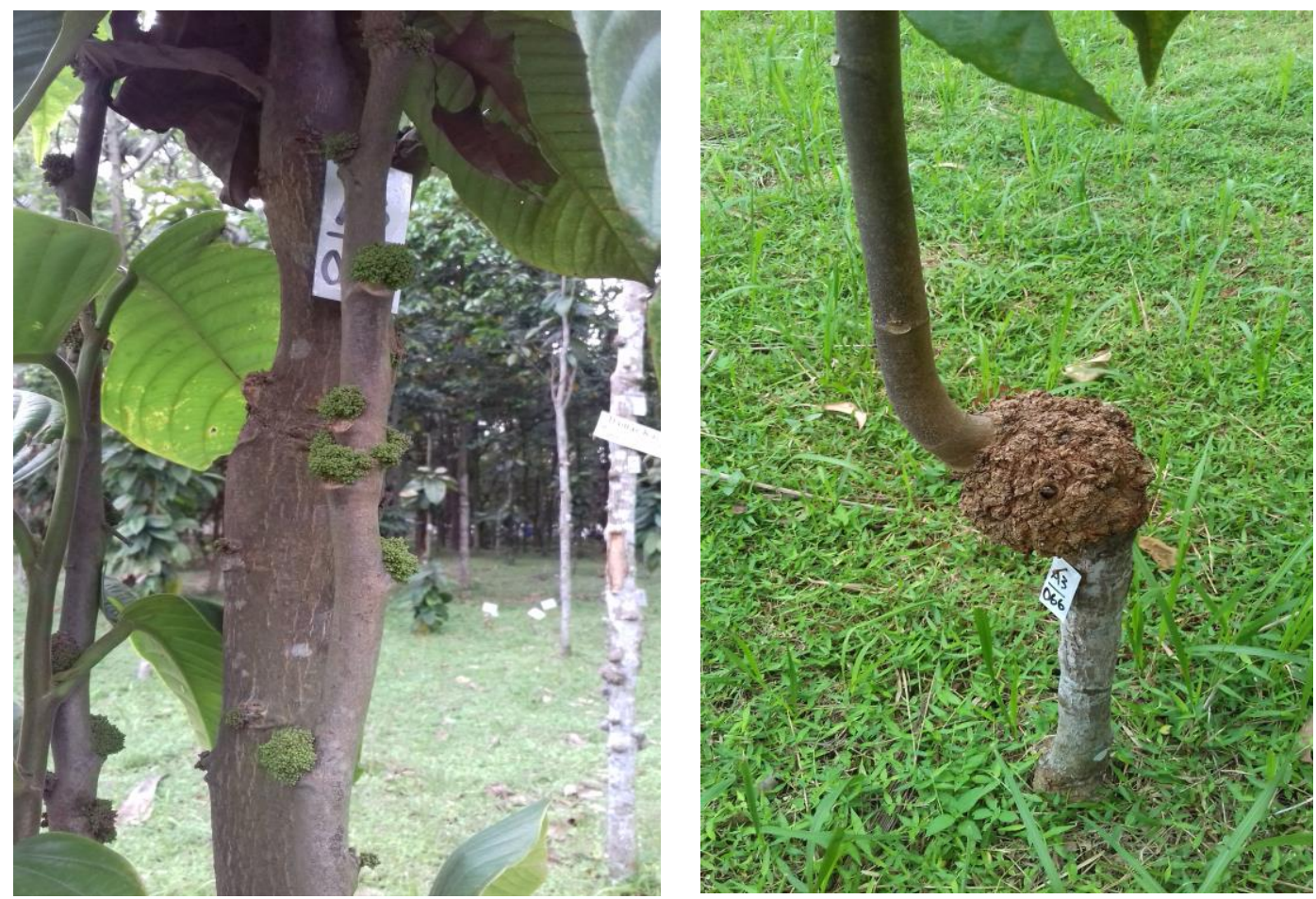

Gambar 3. Benjolan penyakit pada tanaman damar

Akibat yang ditimbulkan oleh penyakit ini adalah terhambatnya pertumbuhan dan perkembangan orgam lain seperti cabang, ranting, daun, bunga dan buah. Bila pada damar terdapat benjolan tersebut, tanaman damar akan terhambat pertumbuhannya kemudian dapat mengalami kematian pada bagian atas cabang. Bagian yang mati tersebut akan memunculkan tunas baru, namun tunas yang muncul juga mengalami pertumbuhan yang tidak normal. Selain karena beberapa faktor seperti kondisi lingkungan dan hama penyakit, kurangnya perawatan dan tindakan silvikultur pada tanaman damar juga dapat menjadi faktor penyebab terhambatnya pertumbuhan damar. Sehingga perawatan dan tindakan silvikultur yang tepat sangat dibutuhkan untuk tanaman damar di Universitas Lampung. Selain itu juga dapat diakibatkan oleh kurangnya perawatan tanaman ini. Atau dengan kata lain tanaman ini memerlukan penanganan sisi silvikultur yang sampai saat ini sedikit terabaikan.

\section{Kesimpulan dan Saran}

\subsection{Kesimpulan}

Pertumbuhan tanaman damar mata kucing di Universitas Lampung yang berumur 14 tahun sangat lambat dengan tinggi rata-rata hanya sebesar 3,22 m dan rata-rata diameter batang hanya sebesar $6,00 \mathrm{~cm}$. Terdapat beberapa faktor yang menghambat pertumbuhan damar mata kucing di Universitas Lampung antara lain adalah faktor tempat tumbuh dan mikroorganisme.

\subsection{Saran}

Sebaiknya dalam budidaya damar, teknik-teknik budidaya dan silvikultur lebih diperhatikan secara benar agar produktivitas damar lebih meningkat. 


\section{Referensi}

[1] Wikipedia (2019) “Shorea”, From Wikipedia the free encyclopedia, Diakses: https://en.wikipedia.org/wiki/Shorea, pada tanggal 29 Juli 2019.

[2] Hadiyan, Y. (2015) "Pentingnya integrated approach dalam konservasi keragaman jenis dan sumberdaya genetik damar mata kucing di Kabupaten Pesisir Barat, Lampung." Jurnal Pros Sem Nas Masy Biodiv Indon 1 (4):702 - 706.

[3] Syam, T., Kushendarto, Bintoro, A., Indriyanto. (2007) "Keanekaragaman Pohon di Kampus Hijau Unila", Bandar Lampung, Penerbit Universitas Lampung

[4] Harianto, S.P., Dewi, B.S., Rusita. (2016) “Repong Damar”, Yogyakarta, Plantaxia 